\title{
Study on the change of soil temperature in Ground Source Heat Pump System
}

\author{
Shili Han ${ }^{1, a^{*}}$, Shunyu Su ${ }^{1, b}$, Lamei Liu ${ }^{1, c}$, Chuanhui Zhou ${ }^{1, d}$, Lei Shi ${ }^{2, e}$ \\ ${ }^{1}$ College of Urban Construction, University of Science and Technology, Wuhan 430065, China \\ ${ }^{2}$ Zhejiang Loopmaster Energy Technology Co, Ltd, Hangzhou 310051, China

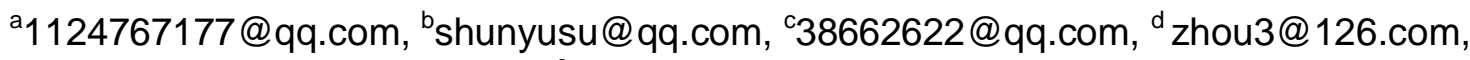 \\ e176785813@qq.com
}

\begin{abstract}
Keywords: Buried pipe; Simulation; Transition period; Thermal equilibrium
Abstract. Based on cylindrical source model, heat transfer process between the underground pipes and the soil was simulated. The feasibility of this simulating method was validated by comparing its results with the temperature data obtained from the existing ground source heat pump test platform. Thus this method was applied to simulate the year-round operation of the ground source heat pump, study the impact of its operation on underground thermal equilibrium and analyze the thermal recovery ability of the soil. The results show that the long-running of ground source heat pump system will lead to the underground heat accumulation phenomenon in Wuhan. There is a tendency for soil temperature to recover the initial temperature during the transition period. The rational use of temperature recovery capability by soil itself will contribute to solve the problem of soil heat accumulation, and benefit to regulate underground thermal equilibrium.
\end{abstract}

\section{Introduction}

The ground source heat pump (GSHP), as an energy-saving air conditioning technique, is utilizing the renewable ground thermal power that comes from solar energy. Lots of research were carried out about the ground source heat pump. The focus of the research contents are similar. In the areas with hot summer and cold winter, the soil cold or heat accumulation of GSHP system has been the hot issue. As the load imbalance in winter and summer, the underground energy injection and absorption of GSHP system are inequality. The long-running of GSHP system will lead to the underground heat accumulation phenomenon.

In order to solve the problem of the soil heat accumulation, the change of soil temperature should be understood first. Only through simulation can let us know about long-term changes in soil temperature in a short time. To establish a correct model is the key of the simulation. In the $1940 \mathrm{~s}$, line heat source model was put forward for the first time by Ingersoll ${ }^{[1]}$. The line heat source model is the basic idea of buried pipe that heat exchanger is supposed as a infinite long, constant heat flux line heat source, and its heat transfer is one dimensional unsteady heat conduction problems. Kavanaugh put forward a cylindrical source model that make cylindrical heat source solution to determine the single tube heat transfer rate of the soil around and the temperature as exact solution ${ }^{[2]}$. The cylindrical source model has higher simulation accuracy than line heat source model. The results are more credibility ${ }^{[3]}$. So this model was applied to analyze the heat transfer process between the underground pipes and the soil in this paper.

\section{Simulation of the heat transfer between the underground pipes and the soil}

The Mathematical Model. The thermal physical properties of the soil vary with depth. There are many factors that can influence the thermal physical properties, and the soil stratification of the thermal properties is obvious. The simplified model for convenience of simulation analysis was made in this paper. It assumes that thermal physical properties of the soil around the buried pipe are uniform; The influence of the groundwater seepage is ignored; Buried pipe contact well with soil; The heat exchange between buried pipe and soil is constant; The heat flux on the surface of the buried pipe is 
seen as an inner heat source overlying soil lateral heat dissipation, and the inner heat source is evenly distributed in buried pipe ${ }^{[4][5]}$.

The U-tube heat exchanger is replaced by equivalent single tube heat exchanger. Pipe diameter is given as the following formula ${ }^{[6]}$,

$D_{e d}=(n)^{1 / 2} D_{0}$.

$\mathrm{D}$ is the diameter of $\mathrm{U}$-tube. If it is single $\mathrm{U}$-tube heat exchanger, $\mathrm{n}$ is equal to two; if it is double U-tube heat exchanger, $\mathrm{n}$ is equal to four. The equivalent physical model is shown in Fig.1.

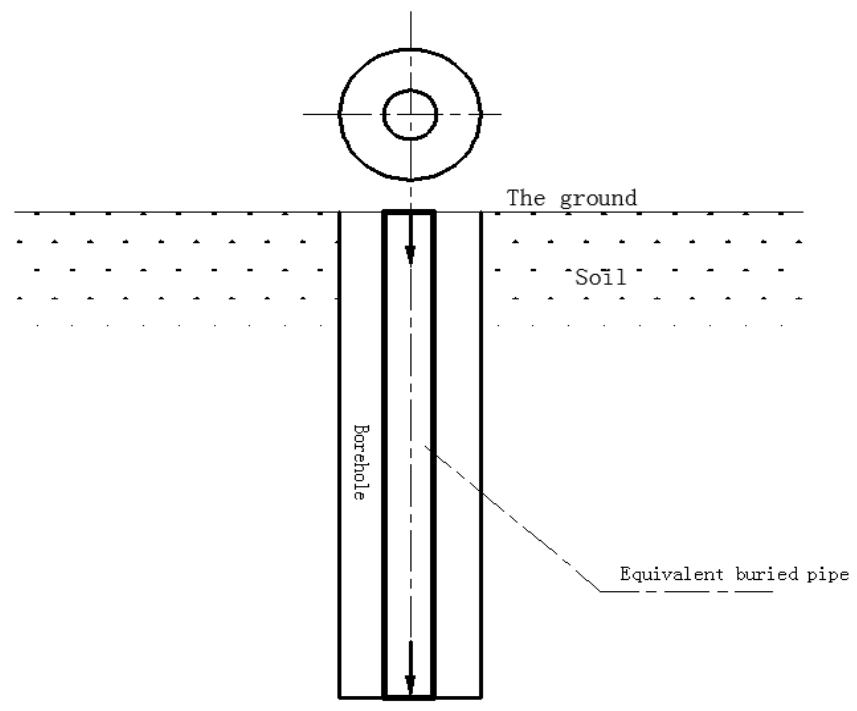

Fig. 1, Sketch of equivalent of diameter pipe

The Initial Conditions and Boundary Conditions. The initial soil temperatures around the buried tube at different depths were set the same at $18.75^{\circ} \mathrm{C}$ according to the buried pipe area. There is no heat transfer between air and surface soil. The space between boreholes is 3 to 6 meters ${ }^{[7]}$. The distance of the farthest border is 6 meters. The constant temperature of the boundary is $18.75^{\circ} \mathrm{C}^{[8]}$.

There are three boundares in the heat transfer simulation between the underground pipe and soil. One is the ground, the others are the radial and axial boundaries. The data of the ground temperature come from the hourly ground average temperature in the typical meteorological years. It is selected according to the experiment time of ground source heat pump ${ }^{[9]}$.

The temperature of the radial boundary is expressed as the formula below ${ }^{[10]}$.

$-\lambda \frac{\partial T}{\partial r}=0$

The temperature of the axial boundary is expressed as the formula below.

$$
-\lambda \frac{\partial T}{\partial z}=0
$$

\section{Experimental verification of the model}

Experimental Platform of Soil Source Heat Pump. The laboratory of the ground source heat pump located in the campus of Wuhan University of Science and Technology. Data acquisition systems are divided into two parts, which are the independent research and development of ground source heat pump energy efficiency monitoring system and the underground soil temperature monitoring system.

There are sixteen vertical buried tubes and two horizontal buried pipes. The sixteen buried tubes are divided into three buried-districts. All of the depths of the sixteen pipes are 100 meters. The backfill materials are virgin pulp and yellow sand with 1:1 proportion of mixture.

Verification of the Results of the Simulation. The ground source heat pump system starts intermittent operation from 20th July, 2015. The operation time of the system is 8:00-17:00 every day. 
The number one buried pipe in first buried-districts was simulated in this paper to explore the change of soil temperature near the tube from July 20th to August 5th. The model was validated by comparing the experimental data with the simulation of soil temperature around buried pipes.

The experimental values of soil temperature and the simulation values of the soil embedded depth of 100 meters in July 28th and August 2nd are analyzed in this paper. The comparing results are shown in Fig.2 and Fig.3.

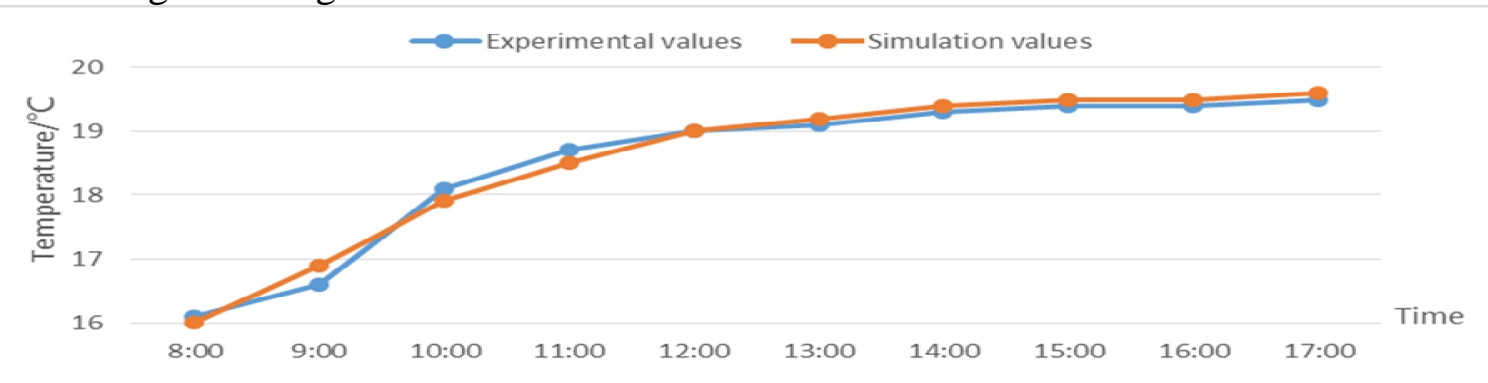

Fig.2, The change of the soil temperature in 28th July

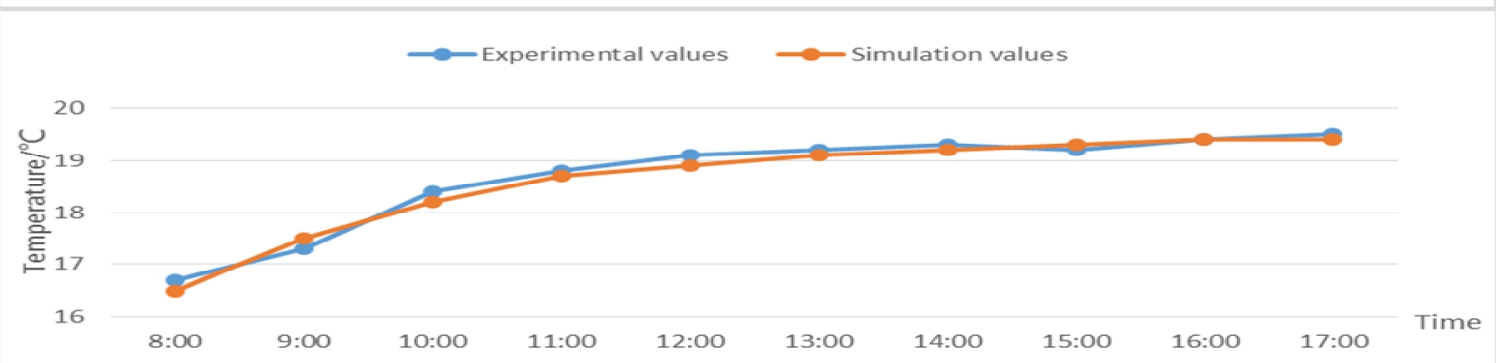

Fig.3, The change of the soil temperature in 2nd August

The above figures show that the simulation values and experimental values are very close in July 28th and August 2nd. The change trend of temperatures is consistent. The average errors of simulation values are $0.7 \%$ and $0.8 \%$ in the two days. The maximum deviation between simulated temperatures and real temperatures is $0.3^{\circ} \mathrm{C}$. The average temperature deviation is lower than $0.2^{\circ} \mathrm{C}$. It can be seen from the above analysis that the cylindrical source model is reasonable. There is high precision and reliability in the simulating results of the buried pipes.

\section{Research of soil temperature recovery ability}

Further simulation was made about the heat transfer of three buried pipes, which are number one pipe in the first buried-district, number six pipe in the second district and number twelve pipe in the third district respectively. It is supposed that the calculating period for heating is from December 15th to March 15th of the next year, and the calculating period for cooling is from June 1st to September 30th according to heating and cooling demands of Wuhan. Figure 4, figure 5 and figure 6 show the temperatures around the buried pipes in different depths from December 2013 to August 2015.

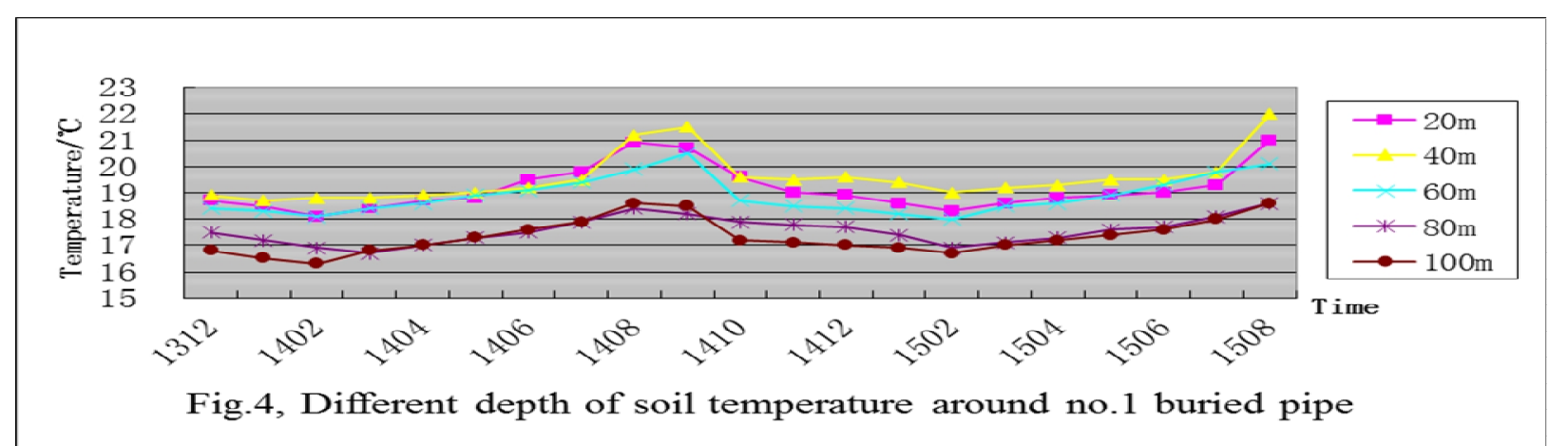



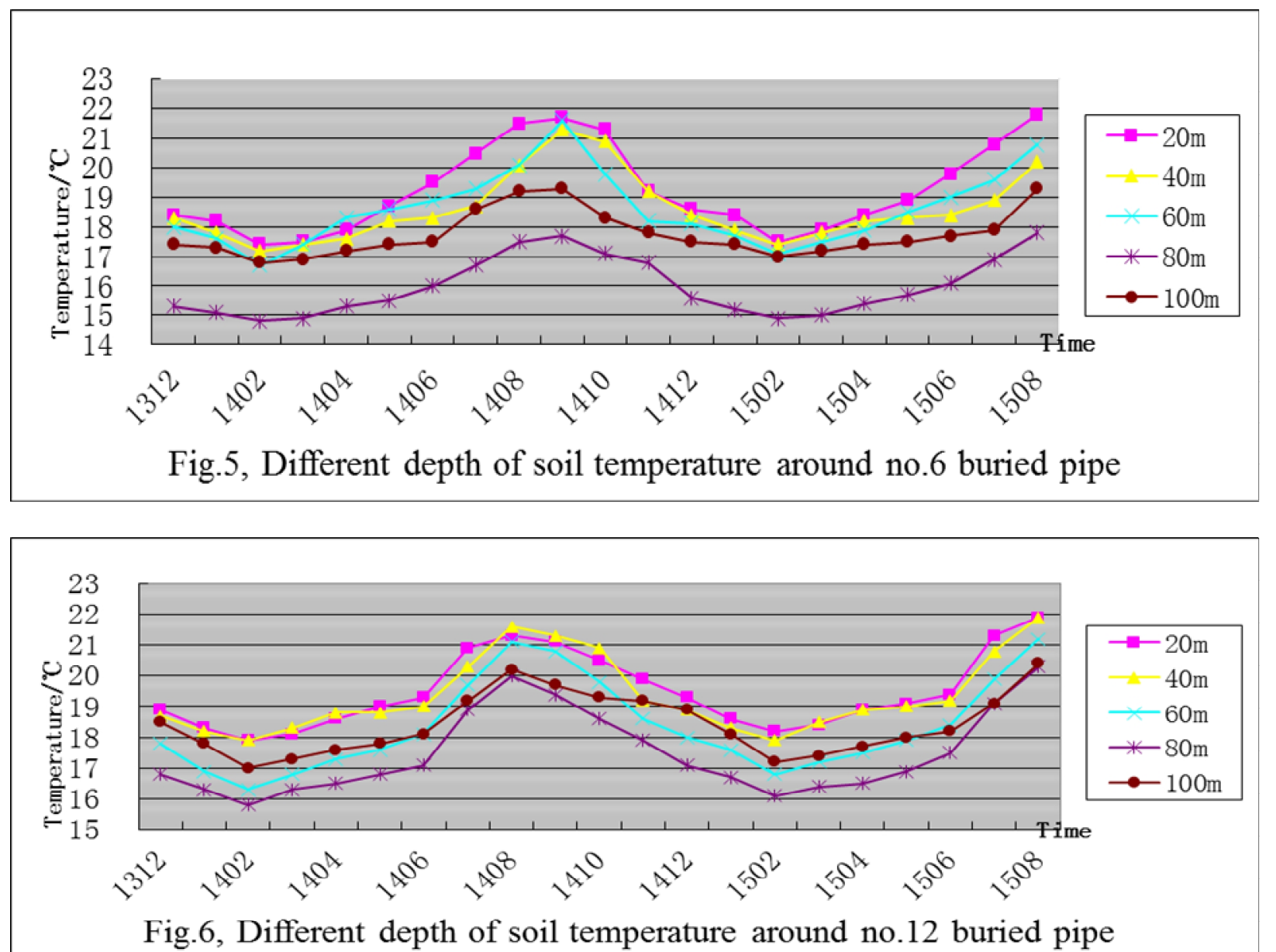

The above figures show that the changes of soil temperatures around the buried pipes in different depths are identical. The soil temperatures around buried pipes drop by $1.6^{\circ} \mathrm{C}$ from December 2013 to February 2014. The temperatures are continuously increasing from March 2014 to September 2014. The temperatures rise slowly from March to September and rise fast from June to September. The increasing ranges are $1.5^{\circ} \mathrm{C}$ and $2.1^{\circ} \mathrm{C}$ respectively. The temperatures are continuously decreasing from October 2014 to February 2015. The temperatures drop fast in October and drop slower from November to February 2015. The decreasing ranges are $0.8^{\circ} \mathrm{C}$ in October, $1.0^{\circ} \mathrm{C}$ from November to December and $1.6{ }^{\circ} \mathrm{C}$ from December to February 2015 respectively. The temperature change trend from March 2015 to August 2015 is similar to that in 2014.

Since the heating period is from December to February next year, the GSHP system runs in this period. The soil temperature drops significantly because of the heat exchanger. The system doesn't run from March to May. This period is known as the first transition in this paper. The soil is in a state of heat recovery. The temperature of the soil rises at the rate of $0.5{ }^{\circ} \mathrm{C}$ per month. The system begins to run again after June. The cooling period is from June to September. And the soil temperature rises quickly in this period. When it comes to October, the temperature begins to drop after the system stops running. It is known that the second transition is from October to December in this paper. The soil is in a state of cold recovery and the temperature of the soil drops at the rate of $0.6{ }^{\circ} \mathrm{C}$ per month.

The soil temperatures from January to August in 2014 and in 2015 are compared in this paper to investigate the change of the temperatures over time. The temperature at the depth of 80 meters is analyzed because the surface temperature is strongly influenced by the weather. The comparing results are clearly shown in Fig.7. 

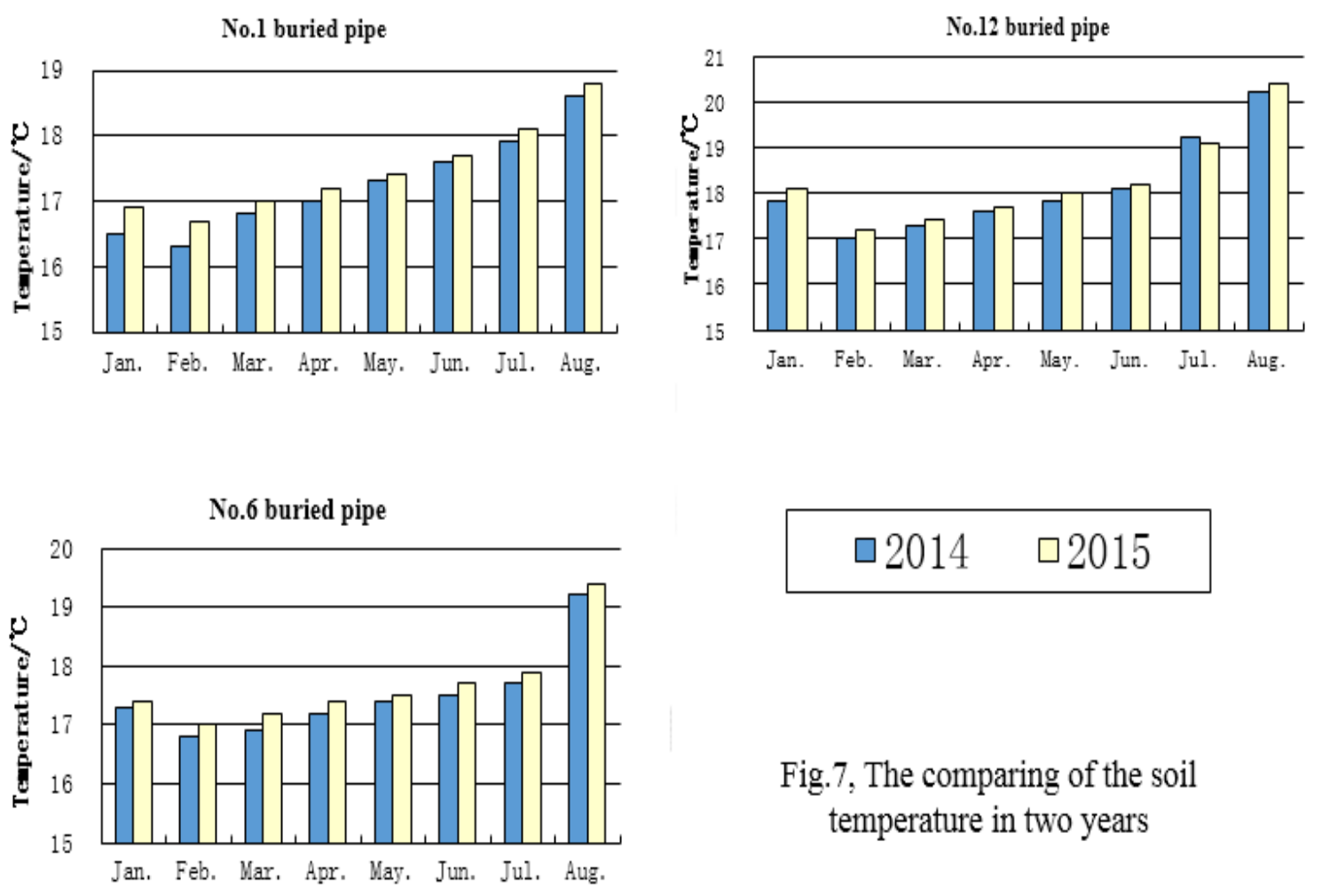

Fig.7, The comparing of the soil temperature in two years

Comparing with the soil temperatures in 2014, the soil temperature in 2015 increase by an average of $0.2^{\circ} \mathrm{C}$. It's the result that the cooling load in summer is greater than the heating load in winter in Wuhan. The excess heat in soil leads to the rise of the soil temperature. Therefore the soil temperature will get more and more high, and the system gradually becomes less efficient.

The above analyses represent that there is a trend that soil temperature will return to the original temperature during the transition period. So the underground thermal balance can be adjusted according to the ability of soil recovery. If the using time of air conditioning is reduced in an appropriate range in summer, that is to extend the second transition, the soil temperature will be balanced in theory. But the demanding time for air-conditioner is hard to change because of hot weather, so applying this method is impossible. On the other hand, if the first transition can be shortened, the heat recovery will be reduced. It's conducive to maintain the underground thermal balance. For example, if the air-conditioner is not needed any more in winter, the underground heat can be used to get hot water.

\section{Conclusions}

It is feasible to use the cylindrical source model to simulate the heat transfer between the underground pipes and the soil. And the results have higher accuracy and credibility.

The problem of the imbalance between cooling load and heating load in Wuhan is obvious. The soil temperature increases at an annual rate of $0.2^{\circ} \mathrm{C}$. If this problem cannot be solved properly, the temperature of underground soil will gradually rise inevitably, and it will affect the normal operation of GSHP system. The soil temperature has a tendency to return to the original temperature in the two transitions without using GSHP. In the first transition, the temperature of the soil rises at the rate of $0.5^{\circ} \mathrm{C}$ per month. In the second transition, it reduces at the rate of $0.6^{\circ} \mathrm{C}$ per month. It's conducive to maintaining the underground thermal balance to shorten the first transition.

\section{Acknowledgements}

The authors wish to thank the financial support of China Hubei Provincial Natural Science Foundation (No. 2014CFB234) 


\section{References}

[1] Ingersoll L R, P. H. J. Theory of the ground pipe heat source for the heat pump [J]. HPAC, 1948. 20(7): p 119-122.

[2] Ingersoll L R, Z. O. J. Ingersoll A C, Heat Conduction with Engineering, Geological and Other Applications [J]. New York: McGraw-Hill Co, 1954

[3] BERNIER M A Ground-Coupled Heat Pump System Simulation 2001(01)

[4] Zhang Shu, Simulation and experimental validation of soil seasonal thermal storage characteristics by air-U-tube system in severe cold zone. In Chinese. Heating Ventilating \& Air Conditioning, HV\&AC, Vol. 3, 2012

[5] Mao Jinfeng, Chen Shangyuan, Li Yong, Simulational analysis of effect of buried tube heat exchanger on land surface temperature. In Chinese. Journal of PLA University of Science and Technology (Natural Science Edition) Vol. 15 No. 1 Feb. 2014

[6] Liu Zhenghua, Chen Rudong, Li Peng, Liu Shilong, Perform ance study of underground heat exchanger in soil source heat pump system. In Chinese. Fluid machinery, 2007(03)

[7] The ministry of construction of the People's Republic of China. In Chinese. GB 50336 - 2009, Technical specification of ground source heat pump systems engineering technical specification [S]. Beijing: China building industry press, 2009.

[8] Zhang Yufeng, Chen Chengmin, Numerical simulation of heat transfer of soil around U-Tube underground heat exchanger. In Chinese. Journal of Tianjin University, Vol.43 No.8. Aug. 2010

[9] Meteorological information center of China meteorological reference room, Tsinghua university architecture technology scienc. Thermal environment analysis special meteorological data China building. [M]. In Chinese. Beijing: China building industry press, 2005

[10] Zhao Guojun, Simulation and experiment research on ground temperature field around heat exchanger of ground source heat pump. In Chinese. Beijing University of architecture. 